$\begin{gathered}\text { EPiC Series in Education Science } \\ \text { Volume 1, 2017, Pages 156-164 }\end{gathered}$
$\begin{gathered}\text { AUBEA 2017: Australasian Universities Build- } \\ \text { ing Education Association Conference 2017 }\end{gathered}$

\title{
Development of a Collaborative Training Partnership in the New Zealand Construction Industry
}

\author{
N. Laing ${ }^{11}$, P. Roberts ${ }^{1}$, L. Kestle ${ }^{1}$, T. Puolitaival' ${ }^{1}$, T. Brenton-Rule ${ }^{2}$ and \\ A. Bryan ${ }^{2}$ \\ ${ }^{1}$ Unitec Institute of Technology \\ ${ }^{2}$ Hawkins Construction \\ nlaing@unitec.ac.nz
}

\begin{abstract}
In 2015 a first tier New Zealand commercial construction company approached the Department of Construction at Unitec regarding the company's professional development training. The primary aim was to focus on introducing a more collaborative best practice approach in a competitive construction environment to some 300 middle management onsite construction staff over a 4-5 year period. The company was seeking a partnership with an innovative tertiary provider to offer specific professional development expertise, and give effect to the company's strategy for ongoing and accelerated growth. The delivery approach needed to have the greatest possible impact on staff in terms of engagement and knowledge transfer. How was this academic-industry partnership built? In this first part of the research, the philosophical and practical approaches, timelines applied by both parties, the steps of how the partnership was developed from the initial interviews through to the developed successful partnership are described. The preparation and delivery of this practically based, real-time bespoke programme alongside the learnings will be described in later stages of the research in a series of publications.
\end{abstract}

Keywords: Collaboration, Building Relationships, Trust, Partnering, Organisational Learning.

\footnotetext{
${ }^{1}$ Lead Author
} 


\section{Introduction}

The construction industry is known as a complex, competitive and often an adversarial environment to work in (Egan, 1988; Egbu, 2004; Latham, 1994). Construction has struggled to maintain productivity and profitability and is accused of low levels of innovation and collaboration, and being poor in knowledge management, not to mention organisational learning (Barlow, 2012; Winch, 2003; Xue et al., 2014). It is difficult to say which one is the cause and which one the effect, but what is certain is that surviving and succeeding in such an environment requires complex responses. Research into the application of innovation, collaboration and organisational learning demonstrates how leveraging these concepts can address productivity and profitability issues in the industry. Skill development and knowledge sharing are seen as the key factors in enabling organisational learning and innovation and through that, an increase in productivity (Esmi and Ennals, 2009).

In late 2015, Hawkins Construction, a tier one New Zealand construction company, approached the Department of Construction at Unitec (Institute of Technology in Auckland, New Zealand) with an opportunity to deliver professional development training to their middle management. At the time, the 'Project Excellence' programme was being delivered by a private training establishment. Discussions between Hawkins and the Department of Construction quickly revealed that the Department had the skills, knowledge and capability to add value to the Hawkins' programme. The only limitation facing the Department was available capacity to develop and deliver the programme, as it was bespoke in nature and would sit outside the Department's normal business model. This study describes how the business venture between Hawkins Construction and the Department of Construction was procured, and resulted in a successful industry-academia partnership, in 2016.

\section{Background}

\subsection{Hawkins}

The Hawkins Group has a long history in the New Zealand Construction Industry and has been steadily growing over the last 70 years. Recently, the company wanted to accelerate growth by lifting revenue. In order to achieve ongoing growth, the professional development of Hawkins staff was seen as an important ongoing strategy. To provide this professional development Hawkins set up a Business School. To guide the School's activities, a framework was established, see Figure 1. A key aim of the School was to provide 'blended learning opportunities' for Hawkins' employees (Wood, 2015). 


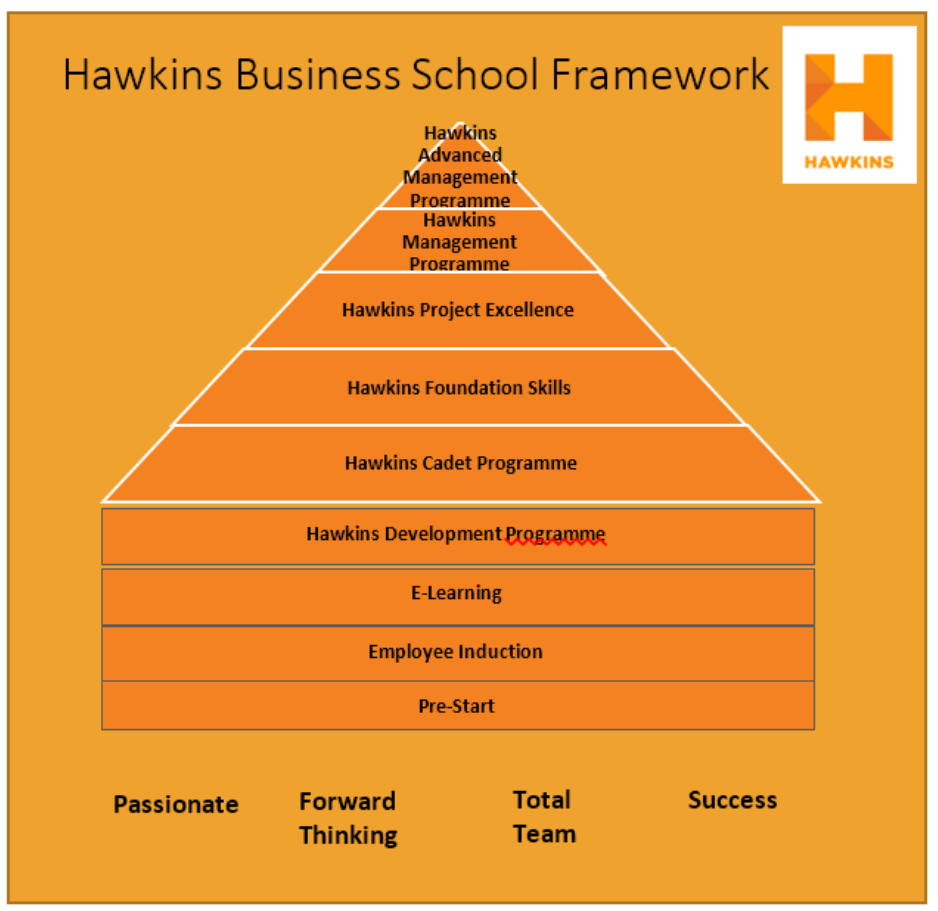

Figure 1 Hawkins Business School Framework

(Source: Brenton-Rule 2016)

The Hawkins' Business School is assisting in the development of the organisation's culture, and in particular, building capacity to innovate and work collaboratively through adopting industry best practice. As a result, the Project Excellence programme for middle tier managers was developed and then delivered for the first time in 2015 , in conjunction with a private training establishment over a period of a year, and consisting of the following modules:

- Excellence,

- Supply Chain Management,

- Collaborative Working,

- Lean Construction,

- Construction Management,

- Project Management.

The programme was delivered to 50 middle tier managers who undertook pre-course work activities and post course assessments (Hawkins Project Excellence Prospectus 2015).

Towards the end of 2015 Hawkins undertook a review of the Project Excellence Programme, finding that whilst the programme had been successfully delivered, there were some aspects that the company felt could be improved. Hawkins decided to contact a number of other educational providers to identify how extra value could be added to the programme. Unitec was one of those providers that were contacted in the latter part of 2015 to discuss the Project Excellence programme and to investigate whether Unitec was interested in getting involved. 


\subsection{Unitec}

Unitec is a government owned Institute of Technology (strictly a Polytechnic under the NZ Education Act 1989), located in Auckland New Zealand and offering tertiary level programmes to domestic and international students. Diminishing government funding for domestic students has meant the Institute has had to operate within tighter budgetary constraints for a number of years. In response to this new environment Unitec reviewed its strategic plan and developed some new key strategic drivers being:

- Meeting the needs of the community

- Enhancing the student experience

- Innovation in teaching and learning

- Being an excellent business (Unitec, 2009).

In line with this strategy, departments within Unitec were encouraged to investigate and expand offerings, including developing short courses and/or professional development programmes. The Department of Construction has been offering undergraduate programmes for over 20 years. The Bachelor of Construction programme is well known by the industry, with the majority of Construction Management and Quantity Survey graduates within the Auckland and international market having studied and graduated from Unitec. The programme has RICS, PACS, NZIQS and NZIOB accreditation. At the time Hawkins approached the Department there was a risk that Unitec may not have been able to provide the support needed in terms of staffing resources to develop and deliver an effective programme for Hawkins. There were a number of significant management changes and institutional changes taking place and these caused a level of disruption in terms of allocating resources and responsibilities.

To mitigate the risk, Unitec's Business Development Unit (BDU) was approached for advice, and it was agreed to work collaboratively together on this opportunity. The first step was to appoint a specialist to the project who had both in-depth construction knowledge and teaching experience. This newly appointed Project Curriculum Advisor (PCA) immediately started working with Hawkins to understand their needs, and this included interviewing attendees of the 2015 course, speaking to Hawkins' Leadership and working with those who had responsibility for the project development programme. The BDU also provided direct input financially as well as advice in the preparation and delivery of the partnership proposal.

\section{Methodology}

A descriptive and interpretive case study research approach has been conducted from the perspective of the main contributors to the industry-academia relationship, being Hawkins and Unitec. Denscombe (2007) identifies a case study as a valuable approach for focusing "on just one instant of the thing that is to be investigated" (p35). In understanding the phenomenon, the use of descriptive and interpretive techniques provides a board opportunity to capture the elements involved, (Liu and Fellows, 2015). In order to apply the interpretive research technique, the case is described in terms of the participants' experiences and drivers. Data has been collected from personal reflections, records of meetings, formal agreements and associated documents established to undertake the delivery of the potential training. 


\subsection{Development Process}

The Head of Department Construction briefed the Project Curriculum Advisor on the approach by Hawkins and what stage the programme negotiations had reached, and this included documentation provided by Hawkins. A meeting was arranged in October 2015 between Unitec and Hawkins' General Manager Human Resources, and the Training and Recruitment Advisor, who provided the background on the company's approach to training and the new initiatives that were put in place. This included the following:

- The Advanced Training programme (facilitated by Auckland University - 2015),

- The Project Excellence Programme (facilitated by the Private Training Institution 2015),

- $\quad$ The Cadet Training programme (facilitated by Wintec in 2016).

These were all new initiatives. Hawkins were pleased with the Advanced Training Programme and had committed themselves to Wintec's inaugural delivery for 2016 of the Cadet Programme. The focus for Unitec at this point was to find out what Hawkins were seeking to achieve in the Project Excellence delivery for 2016.

From the discussion, it was clear Hawkins needed Unitec to respond as pro-actively and quickly as possible and this would set a benchmark for the relationship with Hawkins. The following approach was agreed by the Unitec Project Team:

- Respond within 24 hours as far as practicable,

- Try to actively identify likely issues and provide possible options for consideration,

- Work in partnership and stay focused on the end goal at all times.

After the meeting, written confirmation of the proposed actions was sent within two days highlighting what had been agreed between the parties at the meeting. This quick response was a first step in building a positive partnership with Hawkins, who confirmed that the key points had been identified and this was followed with a "link" phone call between Unitec and Hawkins. Within one week of the initial meeting it was agreed Unitec would undertake further research, in order to clarify Hawkins' specific needs in terms of the Project Excellence Training Programme.

A meeting was arranged for Unitec to interview four of Hawkins' middle manager participants that had attended the Project Excellence Programme, in 2015, followed by meetings with the General Manager Construction and General Manager Infrastructure.

A meeting was also held with potential Unitec delivery facilitators to discuss the partnership opportunity and possible delivery strategies. The idea was met with a sense of excitement, and the meeting turned into a 'Brain Storming' session. The keypoints of which were added to the partnership proposal. In total it took over two months to complete the negotiation process and secure the contract for Unitec, refer Table 1 below as it provides a summary of the timelines involved in the development of the Project Excellence programme.

Time line $\mathbf{- 2 0 1 5}$

14/10 $\quad-$ Initial interview between Unitec and Hawkins

$16 / 10 \quad-$ Respond to meeting with draft of discussions and clarifications (Unitec)

23/10 - Hawkins reply to above discussion and organise meeting with others. (Hawkins) 


\begin{tabular}{|l|l|}
\hline $28 / 10$ & - Meet with previous participants, 2 senior managers (Unitec and Hawkins) \\
\hline $5 / 11$ & $\begin{array}{c}- \text { Meet with the potential Unitec team to formulate a proposal and gain commitment } \\
\text { (Unitec) }\end{array}$ \\
\hline $13 / 11$ & - Submit proposal draft to Hawkins (Unitec) \\
\hline $17 / 11$ & - Hawkins request cost estimates (Hawkins) \\
\hline $17 / 11$ & - Cost estimates submitted (Unitec) \\
\hline $24 / 11$ & - Hawkins enquire as to government funding (Hawkins) \\
\hline $9 / 12$ & - Presentations by Unitec including 2 funding options (Unitec) \\
\hline $16 / 12$ & - Meet with Hawkins to discuss proposals (Unitec and Hawkins) \\
\hline $17 / 12$ & - Confirm that partnership will go ahead (Hawkins) \\
\hline
\end{tabular}

Table 1: Programme Development Timelines

\section{Discussion}

The key drivers that created the successful industry-academia partnership between Hawkins and Unitec resulted from the time spent establishing Hawkins' actual needs and Unitec's willingness and ability to form a meaningful training relationship. Those involved had a mix of construction industry experience, managerial expertise, research and teaching knowledge from diverse construction and management backgrounds and experience. They shared common drivers, being to increase productivity and collaboration in the construction industry. The selected literature used was a selection of relevant published material that underpinned the actions taken by Hawkins' and Unitec when building the collaborative relationship and partnership.

The key success aspect for securing the Project Excellence programme was the importance given by Unitec to developing a strong relationship with Hawkins. The relationship was built on the principles of partnering where trust is developed through open communications. Patterson (2016) identified the importance of effective communications in developing trust and loyalty during the first phase of relationship building. Academic institutions are often cited as being poorly equipped to respond in a flexible way to industry needs (Adler et al., 2011; Schofield, 2013; Tumbas et al., 2016). Therefore, an approach was needed by Unitec to overcome these likely barriers.

Both parties quickly recognised that immediate steps were needed for ensuring that the relationship could be built on trust. However, relationship building for new ventures was not specifically resourced within the Department of Construction. It is not uncommon for businesses to be ill equipped to respond to new ventures (La Rocca et al., 2013). Focusing on relationship building ahead of product needs is considered paramount in new ventures (La Rocca et al., 2013).

A credible point of contact for both organisations proved to be a key success factor and was a key stipulation by Hawkins. This worked well and became a cornerstone of the programme. The PCA appointee was an experienced academic and highly experienced Construction Manager. This offered an opportunity to tailor a bespoke programme that fitted Hawkins commercial needs, and Unitec's academic drivers. Schofield (2013) identified that in order to create successful collaborations where academic and industry knowledge transfer opportunities can exist, there needs to be a strong understanding by academia of the industry contextual drivers. The Hawkins contact person was from a Human Resources (HR) background with a clear focus on providing a value driven training programme. Zhai, Liu, and Fellows (2014) have demonstrated that HR practices can improve organizational performance in the construction industry through mechanisms such as working collaboratively with providers on tailored programmes. This approach did pose a significant commitment by both 
organizations as there was a high level of activity generated throughout the process. It worked because Unitec's PCA had experience in both industries and was able to anticipate a lot of the potential barriers to success. While the Hawkins' person had an excellent understanding of their organisation's personnel and likely constraints. Ankrah (2013) researched into successful instances of University-industry interorganisational knowledge transfer relationships. The development of a theoretical framework by Ankrah, (2013), demonstrated the approach taken by Unitec and Hawkins aligned well in terms of the Formation Phases that resulted in the final organisational structure.

As the relationship developed, it was clear that the underlying philosophy for developing the programme was one of collaboration between Hawkins and Unitec. "A philosophy based on successes drawn from industry, such as increasing innovation and organizational learning, when engaging in this behaviour", (Adler et al., 2011; Cheung et al., 2015). The shared wish to collaborate provided the context Hawkins and Unitec set for this training programme. Oberg (2016) identified that parties that explicitly share their collaborative identities increase their effectiveness. In order to achieve a collective approach, the key for Hawkins was that Unitec was prepared to listen, adapt and offer suggestions. The key for Unitec was that Hawkins was also prepared to listen, adapt and offer suggestions. As a consequence, the relationship was based on a pro-active problem solving approach by both parties.

\section{Concluding Statements}

Early engagement of the Unitec project team played an important role in this successful collaboration. There are many barriers to academic-industry collaboration, as it requires a higher level of commitment and activity (Tumbas et al., 2016). With an effective project team involved, needs were identified and responded to quickly. This proved to be a key step for creating trust in an industryacademic partnership. The result of industry-academic collaboration is the opportunity for new and improved products (Tumbas et al., 2016). Both Hawkins and Unitec were explicit about their focus on building a relationship that was built on trust and collaboration. This focus was key to both how the programme was later developed, and the associated programme content. Success was realized in securing the Project Excellence programme, by not only building a solid collaborative relationship, but also because of the confidence Hawkins had in the Unitec delivery team.

\section{Further Research}

As noted, further publications are planned that will focus on the development of the bespoke programmes and their collaborative and innovative delivery. 


\section{References}

\section{Documents}

Hawkins Project Excellence Prospectus 2015

Unitec. (2009) Unitec Strategic Plan 2010 - 2015

\section{Publications}

Adler, P., Heckscher, C. and Prusak, L. (2011). Building a collaborative enterprise: Four keys to creating a culture of trust and teamwork. Harvard Business Review(July - August), 95-101.

Ankrah, S. (2013). University-Industry Interorganisatinal Relationships for technology/knowledge transfer: A Systematic Literature Review. Retrieved from https://papers.ssrn.com/sol3/papers.cfm?abstract id=2241333.

Barlow, T. (2012). The built environment sector in Australia R\&D investment study: 1992-2010. Retrieved from http://www.sbenrc.com.au/images/stories/BUILT ENVIRONMENT RD.

Brenton-Rule, T. (2016). Hawkins Business School Framework.

Cheung, S. O., Chan, K. Y. and Chow, P. T. (2015). Soft power in construction contracting. In S. O. Cheung, P. Shek, P. Wong and T. W. Yiu (Eds.), The Soft Power of Construction Contracting Organisations (pp. 1-13). New York: Routledge.

Denscombe, M. (2007). Good Research Guide; for small scale social projects (Third ed.): Open University Press

Egan, J. (1988). Rethinking Construction.

Egbu, C. O. (2004). 'Managing knowledge and intellectual capital for improved organizational innovations in the construction industry: an examination of critical success factors'. Engineering, Construction and Architectural Management, 11(5), 301-315.

Esmi, R. and Ennals, R. (2009). Knowledge management in construction companies in the UK. . AI and Society, 24(2), 197-203. doi: http://doi.org/10.1007/s00146-009-0202-9

La Rocca, A., Ford, D. and Snehota, I. (2013). Initial relationship development in new business ventures. Industrial Marketing Managment, 42, 1025-1023.

Latham, M. (1994). Constructing the team.

Liu, A. M. M. and Fellows, R. F. (2015). Research Methods for Construction (Fourth ed.): John Wiley and Sons, Incorporated.

Oberg, C. (2016). What creates a collaboration-level identity. Journal of Business Research, 69, 32203230 .

Patterson, P. (2016). Retrospective: tracking the impact of communication effectiveness on client satisfaction, trust and layalty in professional services. Journal of Services Marketing, 30(5), 485 489.

Schofield, T. (2013). Critical success factors for knowledge transfer collaborations between university and industry. Journal of Research Administration, 44(2), 38-56. 
Tumbas, P., Matkovic, P., Maric, M. and Veselin, P. (2016, 4th-6th July 2016). Organisational aspects of university-industry collaboration. Paper presented at the EDULEARN16, Barcelona, Spain. Retrieved from

Winch, G. M. (2003). How innovative is construction? Comparing aggregated data on construction innovation and other sectors - a case of apples and pears. Construction Management and Economics, 21(6), 651-654.

Wood, A. (2015). Hawkins set to tender on large projects. Retrieved from http://www.stuff.co.nz/business/industries/67156831/hawkins-set-to-tender-on-large-projects

Xue, X., Zhang, R., Yang, R. and Dai, J. (2014). 'Innovation in construction: A critical review and future research'. International Journal of Innovation Science, 6(2), 111-126.

Zhai, X., Liu, A. M. M. and Fellows, R. (2014). Role of Human Resource Practices in Enhancing Organizational Learning in Chinese Construction Organisations. Journal of Management and Engineering, 30(2), 194-204. 